\title{
Variation of water pollution in Taihu Lake Basin by meteorological elements
}

\author{
Wei SONG ${ }^{1, a}$, Chuan-guo ZHANG(Corresponding Author ) ${ }^{2, b}$,Wei YE ${ }^{3, c}$ \\ 1,2,3 Tianjin Research Institute for Water Transport Engineering, M.O.T., Tianjin 300456,China \\ aemail: s56wei@gmail.com, bemail: 13821088542@163.com, cemail: tks_yw@126.com
}

Keywords: Water pollution, Meteorological elements, Taihu Lake Basin.

\begin{abstract}
The correlation analysis of the meteorological data and the weekly concentration of the main water pollutants(COD, $\mathrm{NH}_{3}-\mathrm{N}$ and $\left.\mathrm{DO}\right)$ from seven automatic monitoring stations in Taihu lake basin in 2011 year was carried out. The results showed that there is little correlation between rainfall factors and water quality indicators in meteorological conditions, while temperature factors are related to water quality indicators, but in some heavily polluted stations, correlation will weaken or even disappear.
\end{abstract}

\section{Introduction}

The Taihu Lake Basin is one of the most developed regions in our country. This area basically covers the main rivers into the lake in the upper reaches of the Taihu Lake Basin. The pollution industry is more important, the emission of pollutants is high and the intensity of pollutant discharge is great.

Taihu is the third largest freshwater lake in China with an area of 2400 square kilometers. The lake basin is located in the Yangtze River Delta, located on the south side of the estuary of the lower reaches of the Yangtze River, the North Bank of the Yangtze River, the East and South are adjacent to the sea, and the west and the southwest with the Maoshan Mountains as the watershed. Across the Jiangsu, Zhejiang, Shanghai and Anhui, the total area of the basin is $3.69 * 10^{4} \mathrm{~km}^{2}$. Since the reform and opening up, the social and economic development in the Taihu Lake Basin is very fast. In the region, industrial dense, population accumulation, especially in the northwestern part of Taihu, is particularly serious. The water quality in Taihu deteriorated rapidly in the 90s of last century. The outbreak of eutrophication in Taihu causes water pollution and affects the normal water use of the residents. The cause and control of pollution in Taihu water has always been a hot issue in the study.

The author has analyzed the emission and distribution of the main pollutants of water pollution in the Taihu Lake Basin [1]. Yang Dingtian and Chen Weimin [2] analyzed the temporal and spatial distribution of COD and its related factors in Meiliang Bay of Taihu Lake. Yin Yan, Zhang Yunlin and so on [3][4] have successively studied the temporal and spatial distribution of COD and the correlation with other elements in the northern Taihu lake region and the whole Taihu lake area, In this paper, the main pollutants of water environment in Taihu are taken as the object of study. By analyzing the change trend and correlation of the evaluation indexes of temperature, rainfall and water quality, the function trend of some pollution indexes is obtained. In addition, the source of the main pollutants is analyzed and the relationship between the influencing factors is found and the research and policy basis for controlling and reducing pollution from the source is provided.

\section{Research area}

The scope of this research is Jiangsu Wuxi Shazhu the water quality automatic monitoring station, Jiangsu Yixing Lanshanzui water quality automatic monitoring station, Jiangsu Suzhou Xishan water quality automatic monitoring station, Zhejiang Huzhou Xintang harbor water quality automatic monitoring station, Shanghai Qingpu Jishui harbor water quality automatic monitoring station, Zhejiang Jiaxing Wangjiangjing River water quality automatic monitoring station and Zhejiang Jiaxing Xielu harbor water quality automatic monitoring station. There are seven key water quality 
monitoring stations of the Taihu Lake basin. Table 1 gives the latitude, longitude and cross section information of the seven monitoring stations.

Table 1 location of seven water quality automatic monitoring stations in Taihu Lake Basin

\begin{tabular}{|c|c|c|c|}
\hline Point name & Point latitude and longitude & Rivers & Section condition \\
\hline $\begin{array}{c}\text { Jiangsu Wuxi Shazhu } \\
\text { monitoring station }\end{array}$ & $\begin{array}{c}\text { East longitude } 120^{\circ} 13^{\prime} 46^{\prime \prime} \\
\text { North latitude } 31^{\circ} 23^{\prime} 58^{\prime \prime}\end{array}$ & Taihu & Lake \\
\hline $\begin{array}{l}\text { Jiangsu Yixing Lanshanzui } \\
\text { monitoring station }\end{array}$ & $\begin{array}{l}\text { East longitude } 119^{\circ} 54^{\prime} 43^{\prime \prime} \\
\text { North latitude } 31^{\circ} 12^{\prime} 56^{\prime \prime}\end{array}$ & Taihu & Lake \\
\hline $\begin{array}{c}\text { Jiangsu Suzhou Xishan } \\
\text { monitoring station }\end{array}$ & $\begin{array}{l}\text { East longitude } 120^{\circ} 12^{\prime} 0^{\prime \prime} \\
\text { North latitude } 31^{\circ} 13^{\prime} 0^{\prime \prime}\end{array}$ & Taihu & Lake \\
\hline $\begin{array}{l}\text { Zhejiang Huzhou Xintang } \\
\text { harbor monitoring station }\end{array}$ & $\begin{array}{l}\text { East longitude } 120^{\circ} 50^{\prime} 20^{\prime \prime} \\
\text { North latitude } 30^{\circ} 50^{\prime} 50^{\prime \prime}\end{array}$ & Xintang harbor river & $\begin{array}{c}\text { Zhejiang-Jiangsu } \\
\text { provincial } \\
\text { boundaries } \\
\end{array}$ \\
\hline $\begin{array}{l}\text { Shanghai Qingpu Jishui } \\
\text { harbor monitoring station }\end{array}$ & $\begin{array}{l}\text { East longitude } 120^{\circ} 54^{\prime} 06^{\prime \prime} \\
\text { North latitude } 31^{\circ} 06^{\prime} 56^{\prime \prime}\end{array}$ & Jishui harbor river & $\begin{array}{c}\text { Jiangsu-Shanghai } \\
\text { provincial } \\
\text { boundaries } \\
\end{array}$ \\
\hline $\begin{array}{c}\text { Zhejiang Jiaxing } \\
\text { Wangjiangjing River } \\
\text { monitoring station }\end{array}$ & $\begin{array}{l}\text { East longitude } 120^{\circ} 42^{\prime} 31^{\prime \prime} \\
\text { North latitude } 3^{\circ} 53^{\prime} 06^{\prime \prime}\end{array}$ & $\begin{array}{l}\text { Beijing Hangzhou the } \\
\text { Grande Canale }\end{array}$ & $\begin{array}{c}\text { Jiangsu-Zhengjiang } \\
\text { provincial } \\
\text { boundaries } \\
\end{array}$ \\
\hline $\begin{array}{l}\text { Zhejiang Jiaxing Xielu harbor } \\
\text { monitoring station. }\end{array}$ & $\begin{array}{l}\text { East longitude } 120^{\circ} 42^{\prime} 31^{\prime \prime} \\
\text { North latitude } 30^{\circ} 53^{\prime} 06^{\prime \prime}\end{array}$ & Xielu harbor river & $\begin{array}{c}\text { Jiangsu-Zhengjiang } \\
\text { provincial } \\
\text { boundaries } \\
\end{array}$ \\
\hline
\end{tabular}

\section{Research method}

The correlation coefficient was used to study the correlation between the meteorological conditions and the concentration of pollutants. The correlation coefficient is an indicator of the degree of discretization between the two groups of measured variables. It is used to determine whether the changes in the two sets of measured values are associated. Let $(\mathrm{X}, \mathrm{Y})$ be a binary random variable, then the correlation coefficient is expressed as:

$$
r_{X Y}=\frac{\operatorname{Cov}(X, Y)}{\sqrt{D X \sqrt{D Y}}}
$$

Formula: $\mathrm{r}_{\mathrm{XY}}$ is a correlation coefficients of random variables $\mathrm{X}$ and $\mathrm{Y} . \mathrm{r}$ is a numerical characteristic that measures the degree of linear correlation between $\mathrm{X}$ and $\mathrm{Y}$ in a random variable, Its range of value is $[-1,1]$. The greater the $|r|$ value, the higher the degree of linear correlation between variables; the closer the $|\mathrm{r}|$ value is to 0 , the lower the degree of linear correlation between variables. Generally can be divided into three grades: $|\mathrm{r}|<0.3$ is low linear correlation; $0.3 \leq|\mathrm{r}|<0.8$ is significant correlation; $0.8 \leq|\mathrm{r}|<1$ is highly linear correlation.

\section{Correlation analysis of water quality indicators concentration and meteorological factors in Taihu Basin}

The main meteorological factors affecting water pollution include: temperature, rainfall, runoff, etc. Rrainfall and runoff conditions have a certain dilution and diffusion effect on the concentration of pollutants. Due to the limitation of data acquisition, the relationship between temperature, rainfall and water quality is analyzed only in the weather conditions analysis in this section.

1. The relationship between temperature and water quality indicators concentration

The influence of temperature on the water quality indicators is mainly in seasonal change, the temperature in summer is high, the temperature in winter is low, and the spring and autumn are the transition. Table 2 summarizes the correlation between water quality indicators and temperature of seven sites in the Taihu Lake Basin. 
Table 2 the relevance of temperature and water quality indicators

\begin{tabular}{c|c|c|c|c|c|c|c|c}
\hline Meteorological & Water quality & \multicolumn{7}{|c}{ Site serial number } \\
\cline { 3 - 9 } elements & indicators & 1 & 2 & 3 & 4 & 5 & 6 & 7 \\
\hline \multirow{3}{*}{\begin{tabular}{c} 
Temperature \\
\cline { 2 - 9 }
\end{tabular}} & $\mathrm{DO}$ & -0.890 & -0.770 & -0.680 & -0.824 & -0.621 & -0.242 & -0.612 \\
\cline { 2 - 9 } & $\mathrm{COD}_{\mathrm{Mn}}$ & -0.057 & 0.179 & -0.421 & -0.137 & 0.005 & 0.398 & 0.370 \\
\cline { 2 - 9 } & $\mathrm{NH}_{3}-\mathrm{N}$ & -0.499 & -0.431 & -0.315 & 0.321 & -0.341 & -0.486 & -0.465 \\
\hline
\end{tabular}

From table 2, the correlation between $\mathrm{COD}_{\mathrm{Mn}}$ weekly concentration and temperature is less. And the correlation coefficient is positive and negative, with the exception of site 3 , site 6 and site 7 , the rest are close to 0 . It is considered that there is no linear correlation between the concentration and temperature of the other sites. The correlation between temperature and water quality indicators DO and $\mathrm{NH}_{3}-\mathrm{N}$ weekly concentration is larger, and the $\mathrm{DO}$ weekly concentration of site 1 and site 4 is the most highly correlated with temperature, showing a highly linear correlation.

The purpose of this thesis is to explore the rule. The fitting curve of temperature and indicators concentration is preliminarily obtained by taking three indexes of site 1 (large difference with linear correlation of temperature) as an example, and the specific parameters are not explained in detail.

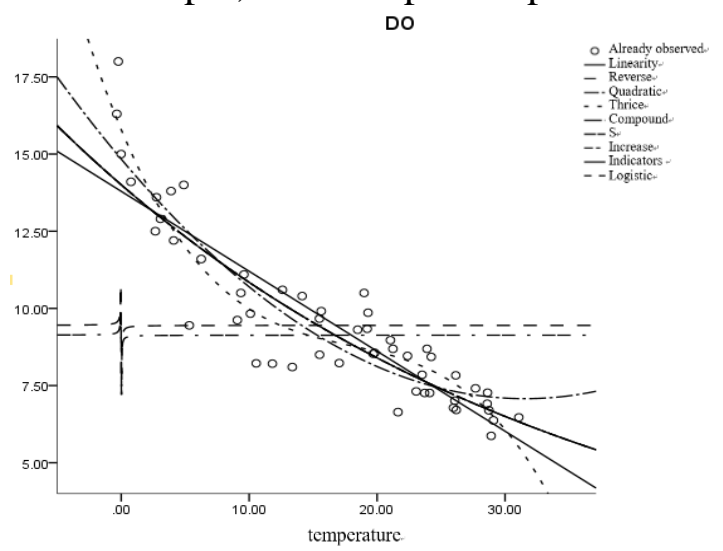

Figure 1 Temperature and DO fitting Figure

Table 3 the relevance of temperature and water quality indicators

\begin{tabular}{c|c|c|c|c|c|c|c|c|c}
\hline & Linearity & Reverse & Quadratic & Thrice & Compound & $\mathrm{S}$ & Increase & Indicators & Logistic \\
\hline $\mathrm{R}$ & 0.890 & 0.294 & 0.916 & 0.940 & 0.910 & 0.270 & 0.910 & 0.910 & 0.910 \\
\hline $\mathrm{R}^{2}$ & 0.793 & 0.087 & 0.839 & 0.883 & 0.827 & 0.073 & 0.827 & 0.827 & 0.827 \\
\hline $\begin{array}{c}\text { The adjustment } \\
\text { value of R }\end{array}$ & 0.788 & 0.068 & 0.833 & 0.875 & 0.824 & 0.055 & 0.824 & 0.824 & 0.824 \\
\hline $\begin{array}{c}\text { Standard error of } \\
\text { estimate value }\end{array}$ & 2.649 & 1.123 & 0.968 & 0.111 & 0.258 & 0.111 & 0.111 & 0.111 & 0.111 \\
\hline
\end{tabular}

As shown in table 3, for the vaule of temperature and the dissolved oxygen with good linear fitting, Quadratic and Thrice fitting effect is better, Increase,Indicators and Logistic fitting effect are also good. It is possible that the compound function regression of higher order or higher order and index will have better prediction model. No further exploration is done here.

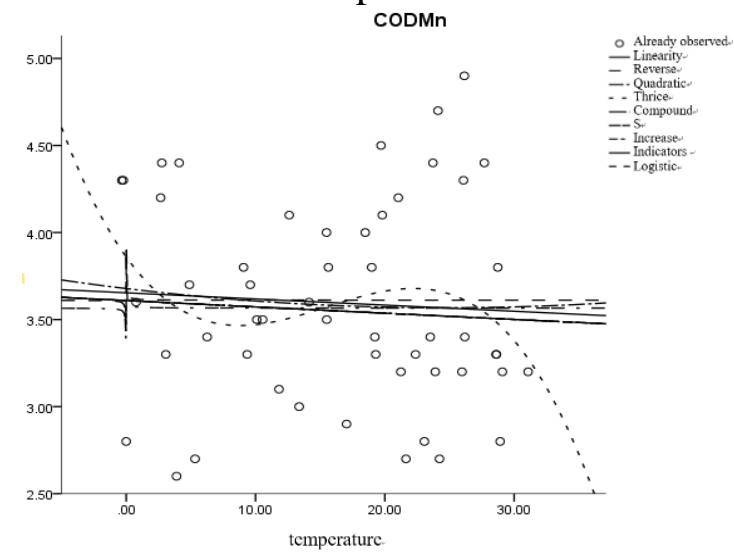

Figure 2 Temperature and $\mathrm{COD}_{\mathrm{Mn}}$ fitting Figure 
Table 4 Temperature and $\mathrm{COD}_{\mathrm{Mn}}$ fitting parameter values

\begin{tabular}{c|c|c|c|c|c|c|c|c|c}
\hline & Linearity & Reverse & Quadratic & Thrice & Compound & $\mathrm{S}$ & Increase & Indicators & Logistic \\
\hline $\mathrm{R}$ & 0.057 & 0.185 & 0.062 & 0.197 & 0.059 & 0.199 & 0.059 & 0.059 & 0.059 \\
\hline $\mathrm{R}^{2}$ & 0.003 & 0.034 & 0.004 & 0.039 & 0.003 & 0.040 & 0.003 & 0.003 & 0.003 \\
\hline $\begin{array}{c}\text { The adjustment } \\
\text { value of } \mathrm{R}^{2}\end{array}$ & -0.017 & 0.015 & -0.037 & -0.021 & -0.016 & 0.020 & 0.016 & 0.016 & 0.016 \\
\hline $\begin{array}{c}\text { Standard error } \\
\text { of estimate } \\
\text { value }\end{array}$ & 0.590 & 0.580 & 0.595 & 0.591 & 0.164 & 0.161 & 0.164 & 0.164 & 0.164 \\
\hline
\end{tabular}

As shown in table 4, for the vaule of temperature and CODMn with extreme difference linear fitting, Reverse, Thrice and S fitting effect are better, but it still can not reach the forecast requirement. As shown in figure 2 , The discrete type of the whole data is too large. The choice of the model needs to be studied.

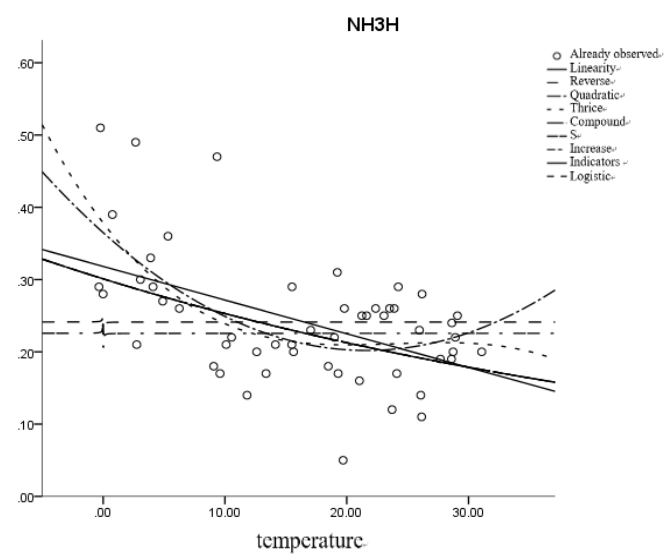

Figure 3 Temperature and $\mathrm{NH}_{3}-\mathrm{N}$ fitting Figure

Table 5 Temperature and $\mathrm{NH}_{3}-\mathrm{N}$ fitting parameter values

\begin{tabular}{c|c|c|c|c|c|c|c|c|c}
\hline & Linearity & Reverse & Quadratic & Thrice & Compound & $\mathrm{S}$ & Increase & Indicators & Logistic \\
\hline $\mathrm{R}$ & 0.499 & 0.071 & 0.583 & 0.590 & 0.428 & 0.085 & 0.428 & 0.428 & 0.428 \\
\hline $\mathrm{R}^{2}$ & 0.249 & 0.005 & 0.340 & 0.348 & 0.183 & 0.007 & 0.183 & 0.183 & 0.183 \\
\hline $\begin{array}{c}\text { The adjustment value } \\
\text { of } \mathrm{R}^{2}\end{array}$ & 0.234 & -0.015 & 0.313 & 0.308 & 0.167 & -0.013 & 0.167 & 0.167 & 0.167 \\
\hline $\begin{array}{c}\text { Standard error of } \\
\text { estimate value }\end{array}$ & 0.077 & 0.089 & 0.073 & 0.073 & 0.350 & 0.386 & 0.350 & 0.350 & 0.350 \\
\hline
\end{tabular}

As shown in table 5, from linearity to thrice, the fitting effect is getting better and better, and the higher fitting may be more consistent with the data.

2. Relationship between rainfall and water quality ndicators concentration

The Taihu basin is in the subtropical monsoon climate. High temperature and rainy in summer and low temperature in winter. The rainfall data are different from the temperature, the discrete type is larger, and there may be a sudden change in rainfall for two adjacent days. As the amount of data is not large enough, and the correlation of rainfall and the concentration of water quality Indicators of each site is analyzed on the whole, as shown in table 6.

Table 6 the relevance of precipitation and water quality indicators

\begin{tabular}{|c|c|c|c|c|c|c|c|c|}
\hline \multirow{2}{*}{$\begin{array}{l}\text { Meteorological } \\
\text { elements }\end{array}$} & \multirow{2}{*}{$\begin{array}{l}\text { Water quality } \\
\text { indicators }\end{array}$} & \multicolumn{7}{|c|}{ Site serial number } \\
\hline & & 1 & 2 & 3 & 4 & 5 & 6 & 7 \\
\hline \multirow{3}{*}{ Rainfall } & DO & -0.318 & -0.399 & -0.315 & -0.248 & -0.352 & -0.134 & -0.322 \\
\hline & $\mathrm{COD}_{\mathrm{Mn}}$ & -0.009 & 0.127 & -0.046 & 0.056 & -0.163 & 0.200 & 0.325 \\
\hline & $\mathrm{NH}_{3}-\mathrm{N}$ & -0.001 & -0.315 & -0.025 & 0.378 & 0.124 & 0.012 & -0.021 \\
\hline
\end{tabular}

From table 6, DO values that are better related to temperature are not related to site 4 and site 6 , and are linearly related to low degrees in other sites.In addition to site 7, the $\mathrm{COD}_{\mathrm{Mn}}$ concentration of other sites is linearly related to the absence of rainfall.For $\mathrm{NH}_{3}-\mathrm{N}$, only site 2 and site 4 are low related with rainfall. On the whole, the linear correlation between rainfall and water quality indicators is not good. 


\section{Conclusion}

The temperature is closely related to the water quality indicators in the meteorological elements, and through many analysis, the direct influence of the rainfall on the index is not outstanding.For temperature, not all sites are consistent with the same relationship. The temperature of site 1-5 has a good correlation with the concentration of DO indicator, and the concentration and temperature show a reverse curve. The concentration of DO decreased with the increase of temperature, the temperature in summer was the highest, and the concentration of DO was the lowest.However, the weekly concentration of DO in site 6 and site 7 is less associated with temperature, it may be that the two sites have serious deterioration of water bodies and have lost their basic self purification capacity.There is almost no linear correlation between $\mathrm{COD}_{\mathrm{Mn}}$ concentration and temperature.For $\mathrm{NH}_{3}-\mathrm{N}$, all of them are relevant, but they are not strong.In addition to site 4 , the temperature is positively correlated with the indicator, and the rest of the sites are negatively correlated.

\section{References}

[1] Song Wei. Study on Water Pollution Change Rule and Source in Taihu Lake Basin [C]. Prof. Dongfang YANG, Henry ZHANG. Proceedings of 2017 International Conference on Traffic Engineering and Transportation System. Riverwood: Aussino Academic Publishing House ,2017: 351-356.

[2] Yang Dingtian, Chen Weimin. Analysis of temporal and spatial distribution and related factors of CODMn in Meiliang Bay of Taihu lake [J]. 2007 Chinese Sustainable Development Forum Chinese Sustainable Development Symposium, 2007(4): 358-362.

[3] Zhang Yunlin, Yang Longyuan, Qin Boqiang, et al. Spatial Distribution of COD and the Correlations with Other Parameters in the Northern Region of Lake Taihu [J]. Environmental Science, 2008, 29(6): 1457-1462.

[4] Yin Yan, Zhang Yunlin, Shi Zhiqiang, et al. Temporal-Spatial Variations of Chemical Oxygen Demand and Biochemical Oxygen Demand in Lake Taihu [J]. Acta Scientiae Circumstantiae, 2010, 30(12): 2544-2552. 